\title{
Size of the diaphragm in chronic bronchitis
}

\author{
R. H. STEELE ${ }^{1}$ and B. E. HEAR D ${ }^{2}$ \\ Department of Pathology, University of Edinburgh
}

\begin{abstract}
Diaphragms were dissected out intact from 29 male and 9 female cadavers at necropsy. Fifteen of the males and eight of the females were grouped as controls, having no history of chest disease. Fourteen of the males and one female gave a history of chronic bronchitis. Point-counting and other methods were employed to measure the mean area, thickness, and volume of the diaphragmatic muscle, excluding the central tendon.

The results showed that the diaphragm was reduced in area, thickness, and volume in the chronic bronchitics, the figures being $350 \mathrm{~cm}^{2}, 0.29 \mathrm{~cm}$, and $99.7 \mathrm{~cm}^{3}$ respectively in male controls, and $295 \mathrm{~cm}^{2}, 0.23 \mathrm{~cm}$, and $68.7 \mathrm{~cm}^{3}$ in the bronchitics. In the female controls, the values were significantly lower than in the male controls. The one female bronchitic had a muscle volume of only $40 \mathrm{~cm}^{3}$. The male controls were similar in height to the bronchitics, but their mean weight was higher, being $69.4 \mathrm{~kg}$ against $56.0 \mathrm{~kg}$ in male bronchitics.

It is concluded that the diaphragm is smaller in chronic bronchitics than in controls at necropsy and that while a major factor in causation is an associated low body weight, other factors such as the mechanical consequences of flattening of the diaphragm, longstanding reduction in physical activity, and other diseases such as cancer may also play a part. No histological changes by nonquantitative methods were found in the diaphragm in the chronic bronchitics, but muscle fibre shrinkage was suspected. By contrast, a few cases of asthma examined to date have shown no evidence of reduction in diaphragm size. The mechanical implications are discussed.
\end{abstract}

Modern quantitative methods derived from the studies of geologists in the 1930s have been adapted by fathologists to measure changes in various tissue components in disease. In chronic bronchitis and emphysema, for example, the methods have been used to demonstrate enlargement of the bronchial mucous glands and hyperplasia of bronchial smooth muscle (Heard, 1969). The amount of emphysema in a specimen of lung can be measured accurately by a choice of several different procedures. Such information, especially when compared with clinical and physiological data from the same patients, is improving our understanding of chronic bronchitis and emphysema and helping to raise standards of treatment.

Physiologists and radiologists have studied the normal functions of the diaphragm by various methods (Keefer, 1957 ; Bergofsky, 1964 ; Boyd, 1969; Mognoni, Saibene, and Sant 'Ambrogio, 1969; Simon, Bonnell, Kazantzis, and Waller, 1969) and have reported the effects of paralysis (Couch, 1953; Douglass and Clagett, 1960; McKelden Smith, 1964), obesity (Lourenço, 1969), and emphysema (Barach and Seaman, 1963). Recently, it has

1Present address: Department of Pathology, The University, Southampton

2Present address: Department of Pathology, Brompton Hospital, London S.W.3, and London Chest Hospital, E.2 been shown that the excursions of the diaphragm, as measured radiologically, are directly proportional to the compliance of the lungs (Milne and Bass, 1969).

In the present study, quantitative methods have been adapted to measure the area, thickness, and volume of muscle in the human diaphragm at necropsy. Diaphragms from chronic bronchitics were compared with others from controls with particular reference to possible hypertrophy or atrophy resulting from the abnormal mechanics of respiration in that disorder.

\section{MATERIALS AND METHODS}

Diaphragms were examined from 29 males and 9 females. Fifteen of the males gave no history of pulmonary disease in life and were termed controls, and 14 gave a clear history of chronic bronchitis, defined as chronic or recurrent excessive secretion in the bronchial tree occurring on most days for at least three months in the year, during at least two years (Ciba Guest Symposium, 1959). Diaphragms from eight women controls and one woman with chronic bronchitis were also examined.

Approximately one-half of the chronic bronchitics died of their pulmonary disease, the others dying mostly of diseases not related to chronic bronchitis. 
The diaphragms were obtained by a standardized dissection in which the entire muscle, the central tendon, and both crura were excised in one piece. Excess fat was removed and the diaphragm was pinned out flat on a cork board and inverted into a bath of buffered $10 \%$ aqueous formalin for three days for fixation. Excess connective tissue was subsequently trimmed from the muscle of the fixed specimen (Fig. 1).

The central tendon was marked out over transmitted light and excluded from the measurements. The mean area of the rest of the specimen, which was all muscle, was measured by point-counting twice with a transparent hexagonal grid marked with points $1 \cdot 25$ 을 $\mathrm{cm}(0.5 \mathrm{in})$ apart, and by taking the mean of the two readings (which varied by less than $2 \%$ ). The mean thickness of the muscular part was determined by $\mathbb{\Phi}$ making a series of incisions $3 \mathrm{~cm}$ long transverse to the line of the radially arranged muscle fibres and क through the full thickness of the muscle. The incisions $\vec{\circ}$ were made at $1-\mathrm{cm}$ intervals along selected radii. In most diaphragms it was possible to fit 14 radii $\vec{\omega}$ altogether. There was space for five radii on each side of the midline, extending outwards and laterally $\vec{x}$ towards the costal insertions, and a further two on each side of the midline passing more posteriorly to- $\stackrel{\infty}{\circ}$

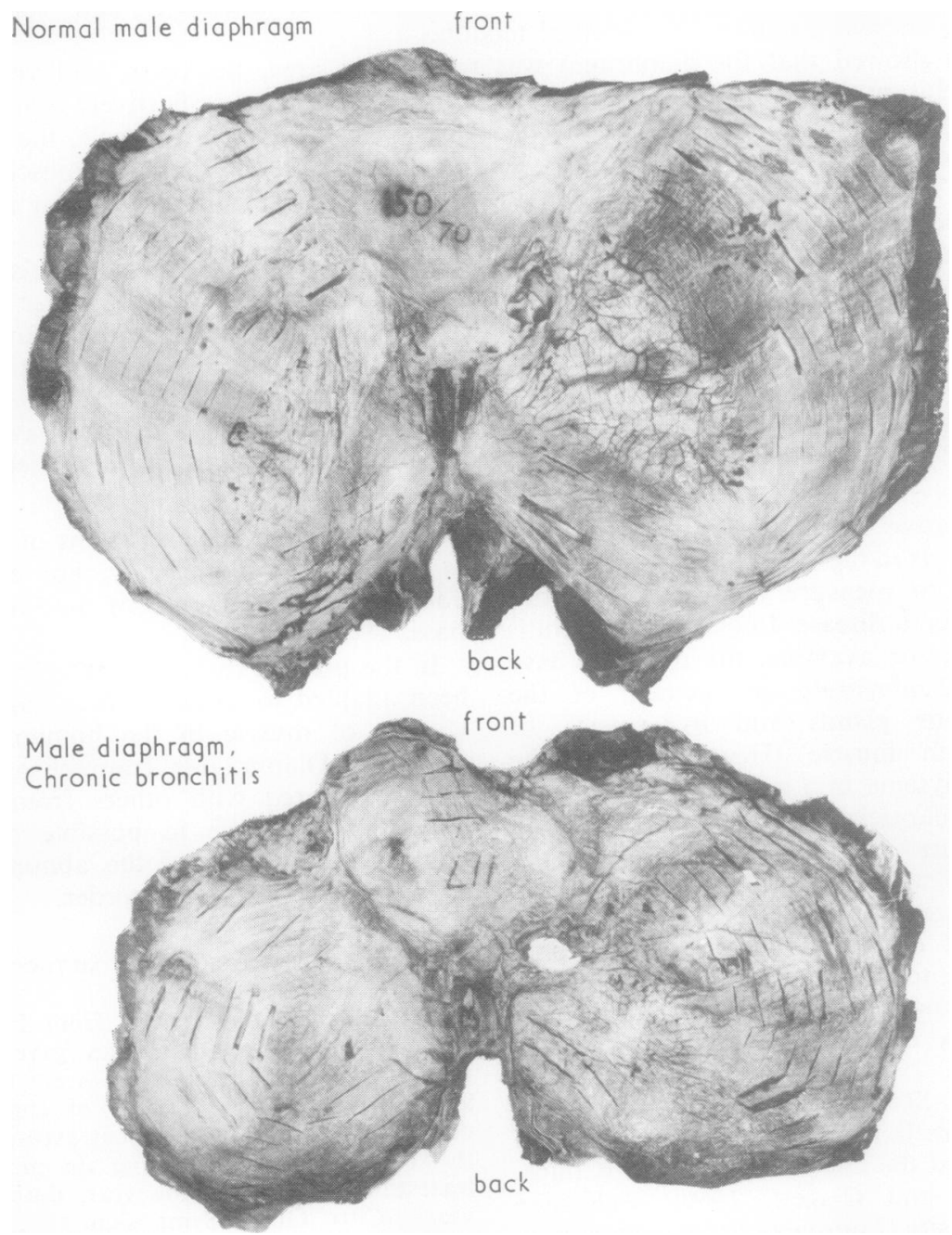

FIG. 1. Comparison of (1) diaphragm from normal male (case 2, upper specimen), and (2) diaphragm from male chronic bronchitic (case 20 , lower specimen). The latter is distinctly smaller than the former. Note also the rows of incisions used to measure muscle thickness $(\times 2)$. 
wards the crura and the psoas and quadratus lumborum (Fig. 1). The number of incisions made at $1-\mathrm{cm}$ intervals obviously depended on the size of the diaphragm and varied in different diaphragms from 55 to 110 , with a mean of 81 incisions. By folding back the diaphragm on each side of an incision completely so that the two cut surfaces lay in the same plane, the double thickness of the muscle could be measured directly with a transparent ruler (Fig. 2). This method

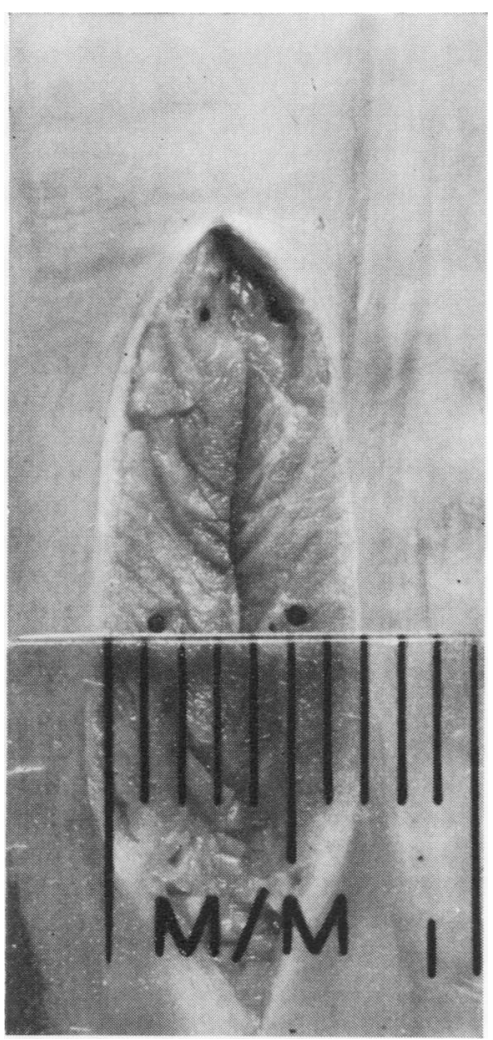

FIG. 2. Method for measuring double muscle thickness. The fat is excluded, giving a reading of $6.5 \mathrm{~mm}$ in this instance.

was quick and had the additional advantage that scar tissue and layers of fat could be recognized easily and excluded from the measurement. The mean double thickness was, of course, halved later.

As a check on the findings and on the effects of prolonged storage in fixation, all measurements were repeated in one-half of the specimens after they had been stored in fcrmalin for periods of up to five months. The repeat counts tended to be very slightly higher than the original counts but differed by less than $5 \%$.

The mean volume of diaphragmatic muscle for each case was taken simply as the product of the mean area and the mean thickness.
Histological examination was made of 66 sections from 12 diaphragms, taken from a variety of muscle thicknesses and all anatomical regions.

The height and weight of the body and the weight of the heart were obtained at the time of necropsy in the usual way, and have been compared with the diaphragmatic measurements in the following account.

\section{RESULTS}

The mean volume of the diaphragmatic muscle in the 14 male chronic bronchitics was significantly less than in the 15 male controls (Tables I and II). The mean mussle volume of diaphragms from female controis was lower than in male controls, and was lower still in the one female chronic

T A B L E I

MEASUREMENTS OF DIAPHRAGMS IN 15 MALE CONTROL PATIENTS WITH NO CHEST DISEASE

\begin{tabular}{|c|c|c|c|c|c|c|c|}
\hline \multirow{3}{*}{ Case } & \multirow{3}{*}{$\underset{\text { (years) }}{\text { Age }}$} & \multicolumn{3}{|c|}{ Diaphragm } & \multirow{3}{*}{$\begin{array}{c}\text { Body } \\
\text { Weight } \\
\text { (kg) }\end{array}$} & \multirow{2}{*}{\multicolumn{2}{|c|}{ Body Height }} \\
\hline & & \multirow{2}{*}{$\begin{array}{c}\text { Mean } \\
\text { Muscle } \\
\text { Thickness } \\
\text { (cm) }\end{array}$} & \multirow{2}{*}{$\begin{array}{c}\text { Mean } \\
\text { Muscle } \\
\text { Area } \\
\left(\mathrm{cm}^{2}\right)\end{array}$} & \multirow{2}{*}{$\begin{array}{c}\text { Mean } \\
\text { Muscle } \\
\text { Volume } \\
\left(\mathrm{cm}^{3}\right)\end{array}$} & & & \\
\hline & & & & & & (ft in) & (m) \\
\hline $\begin{array}{r}1 \\
2 \\
3 \\
4 \\
5 \\
6 \\
7 \\
8 \\
9 \\
10 \\
11 \\
12 \\
13 \\
14 \\
15\end{array}$ & $\begin{array}{l}59 \\
58 \\
59 \\
75 \\
58 \\
45 \\
64 \\
63 \\
71 \\
55 \\
68 \\
62 \\
70 \\
69 \\
46\end{array}$ & & $\begin{array}{l}288 \\
269 \\
357 \\
369 \\
413 \\
300 \\
240 \\
356 \\
350 \\
397 \\
304 \\
406 \\
350 \\
378 \\
370\end{array}$ & $\begin{array}{r}92.2 \\
107.0 \\
103.5 \\
97.3 \\
128.0 \\
108.0 \\
76.8 \\
74.8 \\
91.0 \\
99.2 \\
82.1 \\
117.7 \\
98.0 \\
105.8 \\
114.7\end{array}$ & $\begin{array}{l}60 \\
70 \\
66 \\
60 \\
86 \\
70 \\
57 \\
50 \\
68 \\
78 \\
63 \\
84 \\
70 \\
77 \\
83\end{array}$ & $\begin{array}{rr}5 & 4 \\
6 & 0 \\
6 & 0 \\
5 & 10 \\
6 & 0 \\
5 & - \\
5 & 6 \\
5 & 10 \\
5 & 9 \\
5 & - \\
5 & 4 \\
5 & 9 \\
5 & - \\
5 & 9 \\
6 & 0\end{array}$ & $\begin{array}{l}1.62 \\
1.82 \\
1.82 \\
1.78 \\
1.82 \\
\overline{1.68} \\
1.78 \\
1.75 \\
\overline{1.63} \\
1.75 \\
\overline{1.75} \\
1.82\end{array}$ \\
\hline Iea & $61 \cdot 5$ & $0 \cdot 29$ & 350 & $99 \cdot 7$ & $69 \cdot 4$ & 59 & $1 \cdot 75$ \\
\hline
\end{tabular}

\section{T A B L E I I}

MEASUREMENTS OF DIAPHRAGMS IN 14 MALE PATIENTS WITH CHRONIC BRONCHITIS

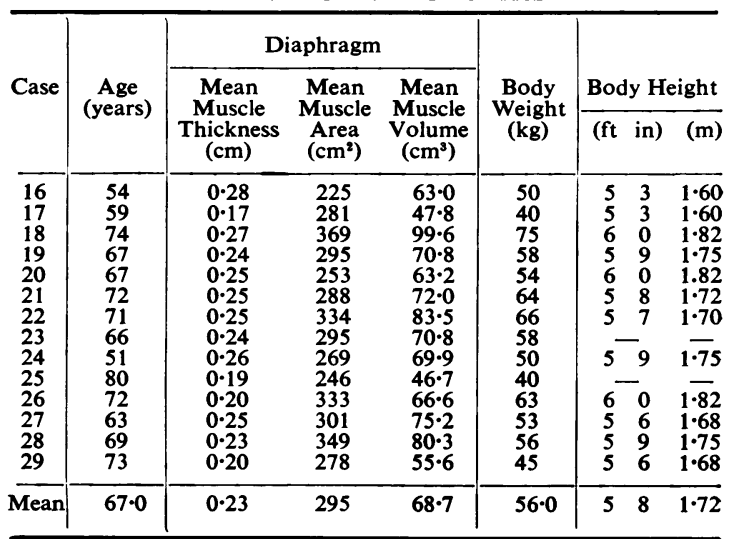


bronchitic available for study at this time. The mean volume of muscle was $99.7 \mathrm{~cm}^{3}$ in male controls and only $68.7 \mathrm{~cm}^{3}$ in male chronic bronchitics. The figure for the seven female controls was $68.7 \mathrm{~cm}^{3}$ (Table III) and only $42.0 \mathrm{~cm}^{3}$ in

T A B L E I I I

MEASUREMENTS OF DIAPHRAGMS IN 7 FEMALE PATIENTS WITH NO CHEST DISEASE

\begin{tabular}{|c|c|c|c|c|c|c|c|}
\hline \multirow{3}{*}{ Case } & \multirow{3}{*}{$\underset{\text { (years) }}{\text { Age }}$} & \multicolumn{3}{|c|}{ Diaphragm } & \multirow{3}{*}{$\begin{array}{c}\text { Body } \\
\text { Weight } \\
(\mathrm{kg})\end{array}$} & \multirow{2}{*}{\multicolumn{2}{|c|}{ Body Height }} \\
\hline & & \multirow{2}{*}{$\begin{array}{c}\text { Mean } \\
\text { Muscle } \\
\text { Thickness } \\
\text { (cm) }\end{array}$} & \multirow{2}{*}{$\begin{array}{l}\text { Mean } \\
\text { Muscle } \\
\text { Area } \\
\left(\mathrm{cm}^{2}\right)\end{array}$} & \multirow{2}{*}{$\begin{array}{c}\text { Mean } \\
\text { Muscle } \\
\text { Volume } \\
\left(\mathrm{cm}^{3}\right)\end{array}$} & & & \\
\hline & & & & & & ( $\mathrm{ft}$ in) & (m) \\
\hline $\begin{array}{l}30 \\
31 \\
32 \\
33 \\
34 \\
35 \\
36\end{array}$ & $\begin{array}{l}60 \\
78 \\
66 \\
57 \\
56 \\
75 \\
75\end{array}$ & $\begin{array}{l}0 \cdot 22 \\
0 \cdot 27 \\
0 \cdot 21 \\
0 \cdot 25 \\
0 \cdot 19 \\
0 \cdot 20 \\
0 \cdot 28\end{array}$ & $\begin{array}{l}326 \\
293 \\
341 \\
276 \\
251 \\
272 \\
314\end{array}$ & $\begin{array}{l}71 \cdot 7 \\
79 \cdot 0 \\
71 \cdot 6 \\
69 \cdot 0 \\
47 \cdot 1 \\
54 \cdot 4 \\
87 \cdot 9\end{array}$ & $\begin{array}{l}70 \\
68 \\
58 \\
41 \\
62 \\
60 \\
70\end{array}$ & $\begin{array}{lr}4 & 11 \\
5 & 5 \\
5 & 6 \\
- & \\
=\end{array}$ & $\begin{array}{l}\overrightarrow{1.49} \\
1.65 \\
1.68 \\
= \\
=\end{array}$ \\
\hline Mean & $66 \cdot 7$ & $0 \cdot 23$ & 296 & $68 \cdot 7$ & $61 \cdot 3$ & 53 & 1.60 \\
\hline
\end{tabular}

the female with chronic bronchitis. Both area and thickness measurements contributed to the lower volume of diaphragmatic muscle in chronic bronchitics. The mean area of muscle was reduced from $350 \mathrm{~cm}^{2}$ for all the male controls to $293 \mathrm{~cm}^{2}$ for the chronic bronchitics (Fig. 1). The mean thickness of muscle was reduced from $0.29 \mathrm{~cm}$ in male controls to $0.23 \mathrm{~cm}$ in male bronchitics.

In female controls, the mean thicknesses, areas, and volumes were less than in the male controls, being $0.23 \mathrm{~cm}, 296 \mathrm{~cm}^{2}$, and $68.7 \mathrm{~cm}^{3}$ respectively. They were in fact similar to the values in male chronic bronchitics.

Only one female chronic bronchitic died during the research period. The mean muscle thickness was $0.20 \mathrm{~cm}$, the mean muscle area $210 \mathrm{~cm}^{2}$, and the mean muscle volume $42.0 \mathrm{~cm}^{3}$.

Applying the Mann-Whitney U Test (Siegel, 1956) to the results, $U$ was found to be 35 for the area $(P<0.02), 17$ for the thickness $(P<0.002)$, and 14 for the volume $(P<0.002)$. This indicates that the probability of such an extreme distribution of results for thickness and volume occurring by chance was less than 1 in 500, and for area less than 1 in 50 .

In order to decide whether the differences between the two male groups were the direct result of chronic bronchitis or were produced by some other variable influenced by chronic bronchitis, the diaphragmatic measurements were plotted against ages, body weights, and heart weights. No significant relationship could be found with age or heart weight. However, some conspicuous associations could be demonstrated with body weight and, to some extent, with bod\& height.

When the mean muscle thickness of the diaphragm was compared with the body weigh the slope of the male control group curve was nog regarded as significant, but that of the male bronchitic group showed a significant correlation af the $5 \%$ level. Although the relationship between the body weight and mean muscle thickness in the male controls was not close enough to be statistie ally significant on its own, it was sufficient to makie the difference in mean thickness between controf and bronchitics most likely dependent on the differences in body weights, because the ratio between weight and thickness in the bronchities was significant.

When the mean muscle area of the diaphragi was compared with the body weight, a closer ass ciation was demonstrated. In the male contra group the correlation coefficient was 0.66 , the slope being given by the equation: Area $=143.5 \mathrm{~N}$ $3.0 \times \mathrm{BW}(t=3.2$ with 13 degrees of freedom This is significant at the $1 \%$ level. For the bronchitics the findings were very simila correlation being 0.68 and area $=142.7+2.7 \times \mathrm{B}$ $(t=3 \cdot 2$ with 12 degrees of freedom). The observest differences in the surface area of the diaphragh between control and bronchitic subjects can attributed mainly to their different body weights?

The mean muscle volume of the diaphrag taken together with body weight distinguishes chronic bronchitics quite sharply from the contro (Fig. 3). Body height adds almost nothing to the distinction and is only slightly correlated with either muscle volume or body weight. High boळy weight or high muscle volume point to controş, low to bronchitics. High and low body height slightly enhance these indications. Body height

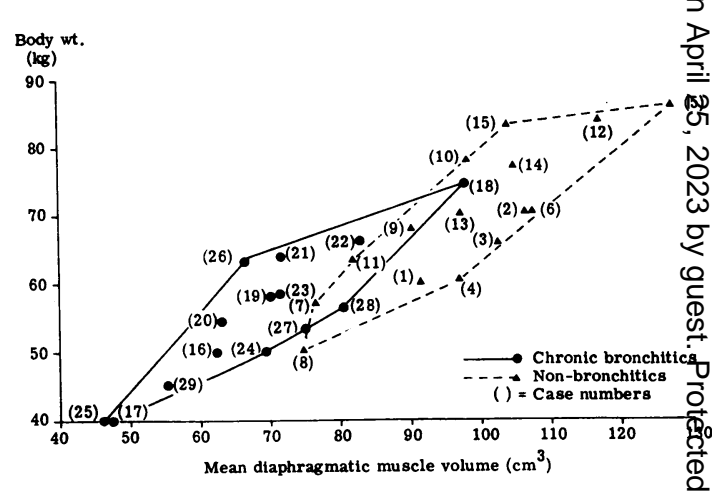

FIG. 3. Comparison of diaphragmatic muscle volu画s and body weights for male chronic bronchitics (inswide continuous lines) and controls (inside interrupted ling) 
alone is a useless indicator, but body weight alone has minor value. Muscle volume alone is a better index than body weight alone. Both together are slightly better than muscle volume alone.

The relationship between mean diaphragmatic volume and body weight in controls and bronchitics is analysed further in Table IV. It

T A B LE IV

RELATIONSHIP OF MEAN DIAPHRAGMATIC MUSCLE VOLUMES TO BODY WEIGHTS

\begin{tabular}{|c|c|c|c|c|c|c|}
\hline & & \multicolumn{5}{|c|}{ Body Weight (kg) } \\
\hline & & $40-49$ & $50-59$ & $60-69$ & $70-79$ & $80-89$ \\
\hline $\begin{array}{l}\text { Mean } \\
\text { diaphragmatic } \\
\text { muscle } \\
\text { volume }\end{array}$ & $\begin{array}{l}\text { Male controls } \\
\text { Male chronic } \\
\text { bronchitics }\end{array}$ & $\begin{array}{c}- \\
50 \cdot 0 \\
(3)\end{array}$ & $\begin{array}{c}75 \cdot 8 \\
(2) \\
70 \cdot 4 \\
(7)\end{array}$ & $\begin{array}{c}93 \cdot 2 \\
(5) \\
74 \cdot 0 \\
(3)\end{array}$ & $\begin{array}{c}103 \cdot 6 \\
(5) \\
99 \cdot 6 \\
(1)\end{array}$ & $\stackrel{120 \cdot 1}{(3)}$ \\
\hline
\end{tabular}

will be seen that there are no controls below $50 \mathrm{~kg}$, and no bronchitics over $79 \mathrm{~kg}$ in weight. Controls and bronchitics show a stepwise increase in volume with increasing body weight. Muscle volumes in bronchitics are all lower than in controls of similar body weight. Furthermore, the muscle volumes are significantly smaller in bronchitics than in controls within the $60-90 \mathrm{~kg}$ range.

Histological examination failed to reveal any consistent abnormality in the bronchitic group. Interstitial fibrosis and fatty infiltration were seen equally in controls and bronchitics. Occasionally a degenerating muscle fibre with a cellular reaction around it was seen, but it was no more frequent in bronchitics than in controls. Muscle spindles were found only occasionally. A pilot trial of quantitating the cross-sectional areas of individual fibres by projecting sections on point-counting screens (MacLeod and Heard, 1969; Hossain and Heard, 1970) revealed a considerable variation in fibre size in sections from different areas of the same diaphragm and between different diaphragms in both series. It was, therefore, clear that in order to obtain valid results by this approach, a very great number of sections would require to be counted, and time was not available for such a large additional undertaking. As far as they went, the results obtained suggested a reduction in fibre size in the diaphragmatic muscle of the bronchitic group.

\section{DISCUSSION}

The results of this study show that most of the diaphragms from this series of male bronchitics had a marked reduction in their mean muscle volumes, compared with male controls. The reduc- tion in volume distinguished the chronic bronchitics quite sharply from the controls, and body height added almost nothing to the distinction. Two of the heavier bronchitics (cases 18 and 22) had normal sized diaphragms.

A direct relationship between simple diaphragm weight and body weight was demonstrated many years ago in the neglected observations of Fromme (1916), and the present study confirms it. We cannot confirm, however, her claim that diaphragm weight correlated with heart weight, partly perhaps because coronary artery disease and hypertension form a greater proportion of necropsies nowadays than in 1916.

The finding of a lower body weight at necropsy in male chronic bronchitics than in male controls has not been recorded before, but clinical workers are familiar with weight loss in severe chronic bronchitis, especially in the terminal stages, and underfeeding through dyspnoea is thought to be important (Wilson, Wilson, and Farber, 1964). However, diaphragmatic muscle volume appears to be a much better index of chronic bronchitis than body weight alone and bronchitics in the same body weight ranges (Table IV) have smaller diaphragms than controls. One explanation may be that the excursions of the diaphragm are greatly limited by persistently inflated lungs and that the dome is flattened. Radiologists are familiar with the poor movements of the diaphragm in chronic bronchitis during screening of the chest. In the present series, the diaphragm was no smaller in those cases in which there was severe emphysema pathologically (cases 19, 20, and 22).

Another explanation for smaller diaphragms may be reduced physical activity due to prolonged chronic bronchitis. We ascertained the occupation and amount of physical activity taken by all our cases in the year before their death. Some of the controls were very fit manual workers who died suddenly (e.g., cases 2,6 , and 15) and they did indeed have large thick diaphragms and their bodies were also heavier than average. Less active patients, such as case 8 who had been hemiplegic for four years before death, had low body weights and case 8 had the smallest diaphragm of the controls.

Clearly, in some of the chronic bronchitics other factors were very important in producing weight loss, e.g., rheumatoid arthritis and oesophageal carcinoma (case 17), and gastric carcinoma (case 25). These two patients had the lowest diaphragmatic dimensions of all the males. There was no correlation between the dimensions of the diaphragm and the number of cigarettes smoked. 
From the physiological point of view it is interesting that the present study shows some evidence of shrinkage of the diaphragm in chronic bronchitis even beyond that explicable by the lower body weight of bronchitics compared with controls. We cannot confirm the claims of others, such as Wyatt, Fischer, and Sweet (1963), that the diaphragm is hypertrophied in chronic airways obstruction. Our findings are more in line with the views of Barach (1956), based on radiographic evidence, that inadequate use predisposed it to atrophy. The flattened diaphragm seen in patients with chronic airway obstruction is a cause of disability not only because of its diminished vertical excursion, but also because it opposes the other muscles of inspiration which attempt to move the ribs outwards (Campbell, Agostoni, and Davis, 1970).

In contrast, although we have not yet studied the diaphragm in sufficient asthmatics to warrant publication at the moment, initial results indicate a work hypertrophy of the muscle not associated with increased area nor with body weight. According to Campbell and co-workers (1970), the diaphragm in asthma appears to contract more forcibly than normally, but because of its poor mechanical advantage, being depressed, it probably contributes less to the external mechanical work of breathing.

In 1928. Hitzenberger claimed to demonstrate atrophy of muscle fibres, interstitial fibrosis, and pseudohypertrophic lipomatous degeneration in the diaphragms of patients with emphysema. More recently, French workers (Brun and Pozzetto, 1958; Brun and Perrin-Fayolle, 1959) have quoted Hitzenberger in support of a hypothesis that pulmonary emphysema has a diaphragmatic aetiology. Our histological examination of diaphragms by light microscopy in the present study has revealed negligible differences between controls and bronchitics. Our pilot quantitative histological study suggested that the only acceptable difference between controls and bronchitics might be shrinkage of muscle fibres relating to the shrinkage observed in the muscle as a whole. There was no special link with emphysema.

We are greatly indebted to Miss Patricia Dugard and Mr. E. F. Harding for help with the statistics. The graph in Fig. 3 was drawn up by Mr. Harding. We also wish to thank Professor G. L. Montgomery for encouragement and advice, Mr. J. Waugh for technical assistance, the Department of Medical Photography, University of Edinburgh, for Figs 1 and 2, and the Department of Medical Photography, Royal Marsden Hospital, London, for Figure 3.

\section{REFERENCES}

Barach, A. L. (1956). Restoration of diaphragmatic functio and breathing exercises in pulmonary emphysema. $N$. St. J. Med., 56, 3319.

— and Seaman, W. B. (1963). Role of diaphragm in chron pulmonary emphysema. N.Y.St.J.Med., 63, 415 . ڤ్

Bergofsky, E. H. (1964). Relative contributions of the rib. cage and the diaphragm to ventilation in man. J. app?. Physiol., 19, 698.

Boyd, W. H. (1969). Co-ordinated electrical activity \& diaphragm and intercostal muscles in rabbits during quiet breathing. Arch. phys. Med., 50, 127.

Brun, J., and Perrin-Fayolle, M. (1959). Insuffisance diâ phragmatique et insuffisance respiratoire chronique. Rev. Prat., Paris, 9, 117.

Brun, J., and Pozzetto, H. (1958). L'emphysème pulmonaite et ses facteurs aggravants d'origine diaphragmatique J. franç. Méd. Chir. thor., 12, 655.

Campbell, E. J. M., Agostoni, E., and Davis, J. N. (1970 $\overrightarrow{\mathrm{A}}$ The Respiratory Muscles. Mechanics and Neural Controf 2nd ed., pp. 151 and 310. Lloyd-Luke, London.

Ciba Guest Symposium (1959). Terminology, definitions, a classification of chronic pulmonary emphysema and related conditions. Thorax, 14, 286.

Couch, A. H. C. (1953). Paralysis of the diaphragm after pneumonia and of undetermined cause. Thorax, 8, 326

Douglass, B. E., and Clagett, O. T. (1960). The prognosis idiopathic diaphragmatic paralysis. Dis. Chest, 37, 29

Fromme, H. (1916). Systematische Untersuchungen über Gewichtsverhältnisse des Zwerchfells. Virchow's Arcg: path. Anat., 221, 117.

Heard, B. E. (1969). Pathology of Chronic Bronchitis and Emphysema, p. 82. Churchill, London.

Hitzenberger, K. (1928). Bewegungsstörungen des ZwercBfells. Klin. Wschr., 7, 315.

Hossain, S., and Heard, B. E. (1970). Hyperplasia of brōchial muscle in chronic bronchitis. J. Path., 101, 171.

Keefer, C. S. (1957). The diaphragm: some reflections on $\overrightarrow{\overline{\text { ts }}}$ function and its diseases. Bull. Johns Hopk. Hosp., 10, 147.

Lourenço, R. V. (1969). Diaphragm activity in obesi J. clin. Invest., 48, 1609.

McKelden Smith (1964). The effect of hemiplegia on te diaphragm. Amer. Rev. resp. Dis., 89, 450.

MacLeod, L. J., and Heard, B. E. (1969). Area of muscle dn $^{\circ}$ tracheal sections in chronic bronchitis, measured ty point-counting. J. Path., 97, 157.

Milne, E. N. C., and Bass, H. (1969). Relationship betwe specific dynamic pulmonary compliance and diaphragmatic excursion. Radiology, 92, 615.

Mognoni, P., Saibene, F., and Sant 'Ambrogio, G. (1960). Contribution of the diaphragm and the other inspiratofy muscles to different levels of tidal volume and static inspiratory effort in the rabbit. J. Physiol. (Lond.), 202, 517.

Siegel, S. (1956). Non-parametric Statistics for the Behavioral Sciences. McGraw-Hill, New York.

Simon, G, Bonnell, J., Kazantzis, G., and Waller, R. E. (1969). Some radiological observations of the range movement of the diaphragm. Clin. Radiol., 20, 231.

Wilson, N. L., Wilson, R. H. L., and Farber, S. M. (19 Nutrition in pulmonary emphysema. J. Amer. diet. 45, 530.

$\bar{W}$ yatt, J. P., Fischer, V. W., and Sweet, H. C. (1963). 角e pathomorphology of the emphysema complex. Part II. Amer. Rev. resp. Dis., 89, 721. 